\title{
Acute effect of Capparis spinosa root extracts on rat articular pain
}

\author{
Mario Maresca ${ }^{a}$, Laura Micheli ${ }^{a}$, Lorenzo Di Cesare Mannelli ${ }^{\text {a,*, }}$, Barbara Tenci ${ }^{a}$, \\ Marzia Innocenti ${ }^{\mathrm{b}}$, Mohamad Khatib ${ }^{\mathrm{b}}$, Nadia Mulinacci ${ }^{\mathrm{b}}$, Carla Ghelardini ${ }^{\mathrm{a}}$ \\ a Department of Neuroscience, Psychology, Drug Research and Child Health - NEUROFARBA - Pharmacology and Toxicology Section, University of Florence, \\ Florence, Italy \\ ${ }^{\mathrm{b}}$ Department of Neuroscience, Psychology, Drug Research and Child Health - NEUROFARBA - Pharmaceutical and Nutraceutical Division, University of \\ Florence, Florence, Italy
}

\section{A R T I C L E I N F O}

\section{Article history:}

Received 11 March 2016

Received in revised form

30 July 2016

Accepted 16 September 2016

Available online 17 September 2016

\section{Keywords:}

Caper root

Spermidine alkaloids

Stachydrine

CFA

MIA

Rheumatoid arthritis

Osteoarthritis

\begin{abstract}
A B S T R A C T
Ethnopharmacological relevance: Capparis spinosa L. originates from dry regions of Asia and Mediterranean basin. In traditional medicine of these areas, infusions from caper root are considered to be beneficial for the treatment of rheumatism, gout and against abdominal pains.

Aim of the study: To evaluate the pain relieving properties of a Syrian cultivar of Capparis spinosa roots in rat models of osteoarthritis and rheumatoid arthritis.

Materials and methods: Decoction (DEC) and hydroalcoholic extract $\left(\mathrm{EtH}_{2} \mathrm{O}\right)$ were obtained from powdered roots; the latter was further separated in $\mathrm{CH}_{2} \mathrm{Cl}_{2}$ and aqueous $\left(\mathrm{H}_{2} \mathrm{O}\right.$-Res $)$ fractions. The extracts were characterized in terms of spermidine alkaloids by HPLC/DAD/MS and stachydrine by NMR. Different amount of free and glycosilated forms of capparispine and analogues (from $0.5 \% \mathrm{w} / \mathrm{w}$ for DEC up to $7.6 \%$ $\mathrm{w} / \mathrm{w}$ for $\mathrm{CH}_{2} \mathrm{Cl}_{2}$ fraction) were detected. Rat models of rheumatoid arthritis and osteoarthritis were induced by the intra-articular administration of Complete Freund's Adjuvant (CFA) or monosodium iodoacetate (MIA), respectively.

Results: Fourteenth days after CFA or MIA injection, the different preparations of Capparis spinosa (3, 30, 100 and $300 \mathrm{mg} \mathrm{kg}^{-1}$ ) were acutely administered p.o.. Powdered roots (300 $\left.\mathrm{mg} \mathrm{kg}^{-1}\right), \quad \mathrm{DEC}$ (100 $\left.\mathrm{mg} \mathrm{kg}^{-1}\right)$, and $\mathrm{EtH}_{2} \mathrm{O}\left(300 \mathrm{mg} \mathrm{kg}^{-1}\right)$ significantly reduced hypersensitivity to mechanical noxious stimuli as well as spontaneous pain evaluated as hind limb bearing alterations in both models. The $\mathrm{CH}_{2} \mathrm{Cl}_{2}$ and the $\mathrm{H}_{2} \mathrm{O}$-Res $\left(30 \mathrm{mg} \mathrm{kg}^{-1}\right.$ ) were the most potent in reverting pain threshold alterations despite the different content of free alkaloids.

Conclusions: Capparis spinosa extracts relieved pain related to rheumatoid arthritis and osteoarthritis after single administration. A synergistic effect due to a specific "phytochemical mixture" is suggested.
\end{abstract} (c) 2016 Elsevier Ireland Ltd. All rights reserved.

\section{Introduction}

Rheumatoid arthritis and osteoarthritis are the most common articular diseases in adults (Goldring and Marcu, 2009). Synovial inflammation, necrosis of chondrocytes and the consequent destruction of cartilage characterize the pathologies (Mullen et al., 2015; Sangha, 2000). Both lead to joint degeneration and are extremely painful (Bijlsma et al., 2011; Scott et al., 2010).

Capparis spinosa L. (Capparidaceae) is a plant originating from dry regions in west or central Asia and particularly spread across the Mediterranean basin (Baytop, 1984; Çalis et al., 1999; Tlili et al., 2011). The traditional use of Capparis spinosa roots against different types of pain in human is well known since the antiquity (Jiang

\footnotetext{
* Corresponding author.

E-mail address: lorenzo.mannelli@unifi.it (L. Di Cesare Mannelli).
}

et al., 2007). Several authors (Al-Said et al., 1988; Sher and Alyemeni, 2010) reported that, in traditional medicine, infusions made from caper are considered to be beneficial for the treatment of rheumatism, gout and abdominal pains; moreover, pastes are used for topic applications to treat swollen joints, skin rashes and burns (Eddouks et al., 2004; Inocencio et al., 2002). The anti-nociceptive and anti-inflammatory properties of Capparis are described in different animal models (Arslan et al., 2010; Zhou et al., 2010). In particular, flowering buds and fruits of Capparis spinosa have shown significant anti-inflammatory and anti-oxidant effects in both in vivo and in vitro model of articular damage (Feng et al., 2011; Panico et al., 2005). Even though the aerial parts of the plant, such as flowers, leaves and fruits are rather studied, less attention has been devoted to the roots of Capparis spinosa. In the Syrian tradition, the powdered root is widely used by oral administration or topical applications on the painful part of "dough" prepared 
mixing the powder with water. In Jordanian traditional medicine, root bark are macerated and placed between gauze on aching area for 15-25 min in order to relieve inflammation and muscle pain (Hudaib et al., 2008). Regarding the root composition it has been reported the presence of alkaloids belonging to the spermidine group (Fu et al., 2008) together with the presence of stachydrine, a more polar alkaloid typical of the caper leaves too (Batanouny and Drissamnauer, 2005; Buckingham, 1994). Interestingly, the use of polyamine alkaloids, as those of the spermidine group, has been suggested as efficacious in arthritis disease (lezaki et al., 2012).

The aim of the present research is the improvement of knowledge about the phytochemical and pharmacological profile of caper root. A Syrian sample of $C$. spinosa root was selected to prepare four different extracts containing alkaloids in order to evaluate their ability in relieving osteoarticular pain. A determination of the alkaloid content was carried out before the in vivo tests. The powered root and the extracts were acutely administered at different dosages, in animal models of rheumatoid arthritis and osteoarthritis.

\section{Materials and methods}

\subsection{Root sample}

The roots of Capparis spinosa L. (Capparaceae; the plant name has been checked with www.theplantlist.org) were collected from KafrNabl, province of Idlib, in the north of Syria, the sample was authenticated by a member of the General Commission for Scientific Agricultural Research, Damascus, Syria. The roots were freeze-dried as whole ( $1 \mathrm{~kg}$ as total) within two weeks after harvest and maintained at room temperature in dark until analyses.

\subsection{Extracts preparation from whole root}

All the extracts were done using $12 \mathrm{~g}$ of fine powdered root and applying the same drug/solvent extraction ratio: 1:30 w/v. The decoction (DEC) was prepared using distilled water under stirring for $1 \mathrm{~h}$, at boiling. After cooling and filtration the supernatant was collected, treated with ethanol $(0.72 \mathrm{~L})$ and kept for $3 \mathrm{~h}$ at $0{ }^{\circ} \mathrm{C}$ to precipitate and remove the crude polysaccharides. After filtration the hydroalcholic solution was dried by rotavapor to obtain DEC sample (about $3 \mathrm{~g} \mathrm{dw}$ ). The hydroalcoholic extraction was performed using ethanol/water mixture $(7: 3 \mathrm{v} / \mathrm{v})$. The first step was a sonication of $30 \mathrm{~min}(35 \mathrm{MHz})$, then two successive extractions, each of $12 \mathrm{~h}$ under magnetic stirring at room temperature, were applied. The hydroalcoholic solutions were recovered after filtration through Whatman filter paper, then gathered together and dried by rotavapor to obtain $\mathrm{EtH}_{2} \mathrm{O}$ sample.

To selectively recover the alkaloids a new hydroalcoholic extract was prepared as described before, but avoiding the final drying. The ethanol was then removed from the sample by rotavapor (t below $30^{\circ} \mathrm{C}$ ), and to the aqueous residue (close to $100 \mathrm{~mL}$ ) was added with $\mathrm{NH}_{3}$ until pH 10.

A liquid-liquid extraction with $\mathrm{CH}_{2} \mathrm{Cl}_{2}(100 \times 2 \mathrm{~mL})$ was applied to treat the alkaline solution, the organic phases were gathered together and dried by rotavapor to obtain $\mathrm{CH}_{2} \mathrm{Cl}_{2}$ extract. The remaining water residue was freeze-dried to obtain $\mathrm{H}_{2} \mathrm{O}$-Res sample. The four extracts previously described were used for the animal tests.

\subsection{HPLC-MS and $M S^{n}$ experiments}

All the dried extracts were redissolved in ethanol/water mixtures to obtain suitable samples for the HPLC analyses.

HPLC-MS and MS ${ }^{n}$ experiments were done in positive mode using two different MS detectors and applying the same elution method. The column was a Fusion with pre-column A $150 \mathrm{~mm} \times 2 \mathrm{~mm}$ i.d., $4 \mu \mathrm{m}, 80 \AA$ (Phenomenex, Torrance, CA, USA); the mobile phases were (A) $0.1 \%$ formic acid/water and (B) $\mathrm{CH}_{3} \mathrm{CN}$. All solvents used were HPLC grade; $\mathrm{CH}_{3} \mathrm{CN}$ was from E. Merck (Darmstadt, Germany). A multi-step linear solvent gradient was applied: $0-2$ min $2 \%$ B; 2-20 min, 2-25\% B; 20-25 min 25-35\% B; $25-28$ min $35-95 \%$ B; 28-32 min 95-95\% with a final plateau of $2 \mathrm{~min}$ at $2 \% \mathrm{~B}$; equilibration time $10 \mathrm{~min}$; flow rate $0.4 \mathrm{~mL} \mathrm{~min}^{-1}$ and oven temperature $26^{\circ} \mathrm{C}$; injection volume $5 \mu \mathrm{L}$.

The UHPLC was a Platin Blue (Knauer, Berlin, Germany), operating in the same condition as described for HPLC-DAD analyses. The UHPLC was directly connected to a LTQ linear quadrupole ion trap mass spectrometer (Thermo Scientific, Bremen, Germany) via an ESI interface. The analyses were performed in scan mode in the range $134-800 \mathrm{~m} / \mathrm{z}$, alternating the two polarities. The following MS parameters were used: spray voltage $4700 \mathrm{~V}$, capillary voltage $20 \mathrm{~V}$, tube lens offset $90 \mathrm{~V}$ in positive ion mode, and spray voltage $-4400 \mathrm{~V}$, capillary voltage $-40 \mathrm{~V}$, tube lens offset $-55 \mathrm{~V}$ in negative ion mode. Nitrogen was used as the sheath, sweep and auxiliary gas at 28, 6 and 4 (arbitrary units), respectively; capillary temperature was $295^{\circ} \mathrm{C}$.

The MS/MS and MS/MS/MS experiments were performed on some selected precursor ions in positive ion mode, at $m / z 144.1$, 598.3 and $436.2 \mathrm{~m} / \mathrm{z}$ as previously described (Khatib et al., 2016).

The HPLC-DAD-TOF experiments were performed on an Agilent 6210 Time of Flight mass spectrometer coupled to an Agilent 1100 HPLC (Agilent Technologies). The chromatographic column and the gradient elution program were the same previously described. Experiments were performed in positive ion mode using a DualSpray ESI source and capillary voltage $4 \mathrm{kV}$. The nebulizer gas was at $20 \mathrm{psi}$ and the drying gas flow and temperature were $6 \mathrm{~L} / \mathrm{min}$ and $350{ }^{\circ} \mathrm{C}$, respectively. The fragmentor voltage was set at $350 \mathrm{~V}$ to obtain an in-source fragmentation of the ions eluting from the ESI spray. Spectra were recorded at 1.03 spectra/s and internally calibrated using the reference mass at $922.009798 \mathrm{~m} / \mathrm{z}$.

\subsection{Determination of stachydrine by ${ }^{1} \mathrm{H} N M R$}

Pure stachydrine (Extrasynthese-Gene) in $\mathrm{D}_{2} \mathrm{O}$ was used to obtain a reference proton spectrum. Different amounts (exactly measured) of DEC, EtH $\mathrm{H}_{2} \mathrm{O}, \mathrm{H}_{2} \mathrm{O}$-Res extracts, were dissolved in $\mathrm{D}_{2} \mathrm{O}$, range $7-12 \mathrm{mg}$ of dried extract per $\mathrm{mL}$. At the same time, exactly known amounts of maleic acid (Merck, purity grade 98\%) were added as internal standard with concentration between 0.74 and $2.5 \mathrm{mg} / \mathrm{mL} \mathrm{D}_{2} \mathrm{O}$. At least three independent ${ }^{1} \mathrm{H}$ NMR experiments, using a $400 \mathrm{MHz}$ instrument Advance 400 (Bruker, Bremen, Germany), were performed for each extract. The singlet of maleic acid at $6.25 \mathrm{ppm}$ was used as reference internal standard, the Me-2 methyl group of stachydrine, at $3.03 \mathrm{ppm}$, was used as reference signal according to a previous works (Khatib et al., 2016).

\subsection{Determination of the spermidine alkaloids by HPLC-DAD}

The quantitative evaluation of the main spermidine alkaloids was performed through the use of $\mathrm{p}-\mathrm{OH}$-coumaric acid as external standard (Sigma-Aldrich, Milan Italy, purity grade $98 \%$ by HPLC), used to build a calibration curve at $280 \mathrm{~nm}$; the linearity range was between $0.22 \mu \mathrm{g}$ and $2.21 \mu \mathrm{g}$, with $\mathrm{R}^{2} 0.998$.

\subsection{Complete Freund's adjuvant-induced inflammatory arthritis}

Male Sprague-Dawley rats were used; for animal's characterization see Di Cesare Mannelli et al. (2013a). Articular damage was induced by injection of complete Freund's adjuvant (CFA, SigmaAldrich) into the right knee joint. Briefly, the rats were slightly 
anesthetized by $2 \%$ isoflurane, the left leg skin was sterilized with $75 \%$ ethyl alcohol, and the lateral malleolus located by palpation; then, a 28-gauge needle was inserted vertically to penetrate the skin and turned distally for insertion into the articular cavity at the gap between the tibiofibular and tarsal bone until a distinct loss of resistance was felt. A volume of $50 \mu \mathrm{L}$ of CFA was then injected (day 0 ). The paw pressure and the incapacitance tests (see below) were performed 14 days after CFA injection.

\subsection{Monoiodoacetate-induced osteoarthritis}

Knee osteoarthritis was induced by injection of monoiodoacetate (MIA, Sigma-Aldrich) into the right knee joint. On day 0 , rats were slightly anesthetized by $2 \%$ isoflurane, the left leg skin was sterilized with $75 \%$ ethyl alcohol, and the lateral malleolus located by palpation; then, a 28 -gauge needle was inserted vertically to penetrate the skin and turned distally for insertion into the articular cavity at the gap between the tibiofibular and tarsal bone until a distinct loss of resistance was felt. Two mg MIA in $25 \mu \mathrm{L}$ saline was delivered into the left articular cavity. The paw pressure and the incapacitance tests (see below) were performed on day 14 .

\subsection{Vegetal extracts treatments}

Powdered roots and all the dried extracts were suspended in 1\% CMC and administered p.o.. The following samples were evaluated: root powder, the decoction (DEC), the hydroalcoholic extract $\left(\mathrm{EtH}_{2} \mathrm{O}\right)$, the methylenchlorid extract $\left(\mathrm{CH}_{2} \mathrm{Cl}_{2}\right)$ and its correlated aqueous residue $\left(\mathrm{H}_{2} \mathrm{O}-\mathrm{Res}\right)$. The doses were empirically chosen on the bases of experimental results.

\subsection{Paw pressure test}

The nociceptive threshold in rats was determined with an analgesimeter (Ugo Basile, Varese, Italy), according to the method described by Leighton et al. (1988). Briefly, a constantly increasing pressure was applied to a small area of the dorsal surface of the paw using a blunt conical probe by a mechanical device. Mechanical pressure was increased until vocalization or a withdrawal reflex occurred while rats were lightly restrained. Vocalization or withdrawal reflex thresholds were expressed in grams. Rats scoring below $40 \mathrm{~g}$ or over $75 \mathrm{~g}$ during the test before drug administration (25\%) were rejected. An arbitrary cut-off value of $250 \mathrm{~g}$ was adopted. Fourteen days after the operation rats were tested twice in $30 \mathrm{~min}$ and mean was shown. Data were collected by an observer who was blinded to the protocol. The half maximal effective dose $\left(E_{50}\right)$ was calculated on the results obtained in this test 30 min after the administration of the different vegetal products in both CFA and MIA model.

\subsection{Incapacitance test}

Weight bearing changes were measured using an incapacitance apparatus (Linton Instrumentation, UK) detecting changes in postural equilibrium after a hind limb injury. Rats were trained to stand on their hind paws in a box with an inclined plane $\left(65^{\circ}\right.$ from horizontal). This box was placed above the incapacitance apparatus. This allowed us to independently measure the weight that the animal applied on each hind limb. The value considered for each animal was the mean of 5 consecutive measurements. In the absence of hind limb injury, rats applied an equal weight on both hind limbs, indicating a postural equilibrium, whereas an unequal distribution of the weight on hind limbs indicated a monolateral decreased pain threshold. Data are expressed as the difference between the weight applied on the limb contralateral to the injury and the weight applied on the ipsilateral one ( $\Delta$ Weight).
Statistical analyses of all behavioral results was performed as decribed previously (Di Cesare Mannelli et al., 2013a).

\section{Results}

\subsection{Composition of the dried extracts (DE)}

DEC sample was obtained by $1 \mathrm{~h}$ decoction mimicking the traditional processes used in the Arab and Greek popular medicine to prepare samples for human applications (Moghaddasi et al., 2012; Sher and Alyemeni, 2010). The extraction by ethanol at $70 \% \mathrm{v} / \mathrm{v}$ coupled with US at low frequency was chosen as the best procedure for recovering the largest amount of spermidine alkaloids (according to Khatib et al., 2016) to prepare the $\mathrm{EtH}_{2} \mathrm{O}$ sample. Aiming to separate the more polar alkaloid, stachydrine, from the spermidine group, a typical fractionation process used to selectively recover lipophilic alkaloid from water was applied obtaining $\mathrm{CH}_{2} \mathrm{Cl}_{2}$ and the $\mathrm{H}_{2} \mathrm{O}$-Res from the fractionation of $\mathrm{EtH}_{2} \mathrm{O}$. Fig. 1 reports the chemical structures of the main spermidine alkaloids and of stachydrine. The HPLC profiles at $280 \mathrm{~nm}$ of the four extracts obtained from caper's root are shown in Fig. 2. The identification of the main group of spermidine alkaloids was done by the help of mass spectrometry according to our previous work (Khatib et al., 2016) representative Extract Ion profiles of the positive ions (by TOF) identifying three main isobars of glycosylated spermidine alkaloids of capparisine and capparispine $(\mathrm{m} / \mathrm{z} 598.27)$ and the corresponding free forms $(\mathrm{m} / \mathrm{z}$ 436.22), together with minor isobaric forms of codonocarpine and isocodonocarpine of monoglycosides are shown in the Supplementary Fig. S1. The corresponding mass spectra with the accurate mass values confirm not only the presence of the alkaloids previously isolated from this root (Fu et al., 2008) but also of several analogous.

\subsection{Alkaloid content in dried extract (DE)}

The evaluation of the spermidine alkaloid was carried out by HPLC-DAD, while the stachydrine was determined by ${ }^{1} \mathrm{H}$ NMR experiment and the data expressed in terms of $\mathrm{mg} / \mathrm{g}$ DE (Table 1 ).

Regarding the HPLC-DAD method the $\mathrm{p}-\mathrm{OH}$-coumaric acid was selected as external standard. Due to the lack of commercially available pure spermidine alkaloids, this acid was chosen in light of the similar chromophoric group present in all the spermidine alkaloids of $C$. spinosa (Fig. 1) and determinant for defining the shape of the correlated UV-Vis spectra. This approach, even if it does not allow an accurate determination of each single compound, has the advantage to be easy and suitable to perform a preliminary study on the alkaloid composition of this root. Similar methods are applied for the analyses of complex vegetal matrices when suitable standards are not available. The ${ }^{1} \mathrm{H}$ NMR measurements were for defining stachydrine content in the DEC, $\mathrm{EtH}_{2} \mathrm{O}$ and $\mathrm{H}_{2} \mathrm{O}$-Res extracts while in the $\mathrm{CH}_{2} \mathrm{Cl}_{2}$ sample this molecule was absent as expected due to its high polarity. Results, obtained by published methodologies (Khatib et al., 2016) are shown in Table 1.

\subsection{Effect of Capparis spinosa on CFA-induced rheumatoid arthritis}

The effectiveness of Capparis spinosa was evaluated on CFAinduced rheumatoid arthritis model in the rat. On day 14, when CFA painful effect peaked, roots $\left(300,100,30\right.$ and $\left.3 \mathrm{mg} \mathrm{kg}^{-1}\right)$, DEC $\left(100,30\right.$ and $\left.3 \mathrm{mg} \mathrm{kg}^{-1}\right), \mathrm{EtH}_{2} \mathrm{O}\left(300,100,30\right.$ and $\left.3 \mathrm{mg} \mathrm{kg}^{-1}\right)$, $\mathrm{CH}_{2} \mathrm{Cl}_{2}\left(30,10\right.$ and $\left.3 \mathrm{mg} \mathrm{kg}^{-1}\right)$ or $\mathrm{H}_{2} \mathrm{O}-\operatorname{Res}\left(100,30\right.$ and $\left.3 \mathrm{mg} \mathrm{kg}^{-1}\right)$ from Capparis spinosa were acutely administered p.o. and behavioral tests were performed. The Paw pressure test lead us to appreciate the reduced pain threshold to a mechanical noxious stimulus (ipsilateral paw) in comparison to the sham + vehicle animals (Figs. 3 and 4). As shown in Fig. 3a, roots sample increased 
<smiles>CC(=O)/C=C/c1ccc(Oc2cc(/C=C/C(C)=O)ccc2O)cc1</smiles>

Cadabicine<smiles>CCCNC(=O)/C=C/c1ccc(Oc2cccc(/C=C\C(=O)NCCCNCCCCNC(=O)/C=C/c3ccc(O)c(O)c3)c2)cc1</smiles>

Capparispine<smiles>C[N+]1(C)CCCC1C(=O)[O-]</smiles>

Stachydrine<smiles>COc1cc(Oc2cc(/C=C/C(=O)NCCCNCCCCNC(=O)/C=C/c3ccc(O)cc3)ccc2O)ccc1/C=C/C(=O)NCCCN</smiles>

Capparisine

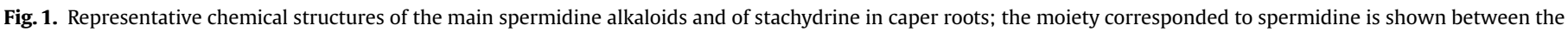
dashed lines.

the pain threshold in a dose-dependent manner. Notably, the higher dose (300 $\mathrm{mg} \mathrm{kg}^{-1}$ ) reverted the CFA-painful effect for $30 \mathrm{~min}$ (Fig. 3a). DEC (100 $\mathrm{mg} \mathrm{kg}^{-1}$ ) completely reduced the mechanical hypersensitivity for $30 \mathrm{~min}$ whereas 30 and $3 \mathrm{mg} \mathrm{kg}^{-1}$ significantly increased the withdrawal threshold for 60 and $30 \mathrm{~min}$, respectively (Fig. $3 \mathrm{~b}$ ). $\mathrm{EtH}_{2} \mathrm{O}$ was fully effective up to $30 \mathrm{~min}$ administration of $300 \mathrm{mg} \mathrm{kg}^{-1}$ (Fig. 3c). The $\mathrm{CH}_{2} \mathrm{Cl}_{2}$ (30$3 \mathrm{mg} \mathrm{kg}^{-1}$ ) fraction significantly lowered the pain sensitivity to a noxious stimulus up to $30 \mathrm{~min}$ peaking $15 \mathrm{~min}$ after administration $\left(64.2 \pm 0.7 \mathrm{~g}, \quad \mathrm{CF}+\mathrm{CH}_{2} \mathrm{Cl}_{2}\right.$ vs $44.6 \pm 0.5 \mathrm{~g}, \mathrm{CFA}+$ vehicle $)$ (Fig. 4a). As depicted in Fig. 4 b, the aqueous fraction $\left(\mathrm{H}_{2} \mathrm{O}-\mathrm{Res}\right)$ reverted mechanical hypersensitivity for $30 \mathrm{~min}$ at the dose of $100 \mathrm{mg} \mathrm{kg}^{-1}$, whereas $30 \mathrm{mg} \mathrm{kg}^{-1}$ significantly increased the painful threshold for $60 \mathrm{~min}$, completely reverting hypersensitivity 15 min after injection $\left(65.8 \pm 0.7 \mathrm{~g}\right.$, CFA $+\mathrm{EtH}_{2} \mathrm{O}$ vs $44.0 \pm 0.6 \mathrm{~g}$, $\mathrm{CFA}+$ vehicle) (Fig. 4b). $\mathrm{ED}_{50}$ values calculated on the bases of this test (CFA, Table 2) allow to establish the following potency order: $\mathrm{H}_{2} \mathrm{O}$-Res $>\mathrm{CH}_{2} \mathrm{Cl}_{2}>\mathrm{DEC}>$ roots $>\mathrm{EtH}_{2} \mathrm{O}$.

On day 14, the difference between the weight burdened on the contralateral and the ipsilateral $\operatorname{limb}(\Delta$ Weight $)$ significantly increased in CFA injected animals with respect to sham+vehicle treated rats as measured by the Incapacitance test (Figs. 3 and 4). As depicted in Fig. $3 \mathrm{~d}$ and $\mathrm{f}$, both roots and $\mathrm{EtH}_{2} \mathrm{O}$ significantly reduced $\Delta$ Weight in a dose-dependent manner peaking $15 \mathrm{~min}$ after injection $\left(14.3 \pm 3.2 \mathrm{~g}, \quad \mathrm{CFA}+\right.$ roots $300 \mathrm{mg} \mathrm{kg}^{-1}$ and $10.7 \pm 2.0 \mathrm{~g}, \mathrm{CFA}+\mathrm{EtH}_{2} \mathrm{O} 300 \mathrm{mg} \mathrm{kg}^{-1}$ ) (Fig. $3 \mathrm{~d}$ and f). Fig. 3e shows that $30 \mathrm{mg} \mathrm{kg}^{-1}$ DEC significantly reduced spontaneous pain for $75 \mathrm{~min}$ peaking $15 \mathrm{~min}$ after injection $(12.9 \pm 0.9 \mathrm{~g}$, CFA+DEC vs $60.0 \pm 2.5 \mathrm{~g}$, CFA+vehicle). Thirty $\mathrm{mg} \mathrm{kg}^{-1} \mathrm{CH}_{2} \mathrm{Cl}_{2}$ extract induced a significant effect for 45 min peaking $15 \mathrm{~min}$ after administration $\left(4.6 \pm 0.3 \mathrm{~g}, \mathrm{CFA}+\mathrm{CH}_{2} \mathrm{Cl}_{2}\right.$ extract vs $60.0 \pm 2.5 \mathrm{~g}$, CFA + vehicle) whereas $\mathrm{H}_{2} \mathrm{O}$-Res, at the same dosage, statistically lowered the hind limb bearing alterations up to $60 \mathrm{~min}$ (at $15 \mathrm{~min}$ : $57.0 \pm 1.3 \mathrm{~g}, \mathrm{CFA}+\mathrm{H}_{2} \mathrm{O}$-Res vs $65.0 \pm 3.0 \mathrm{~g}, \mathrm{CFA}+$ vehicle) (Fig. $4 \mathrm{c}$ and $\mathrm{d}$ ). Furthermore, $100 \mathrm{mg} \mathrm{kg}^{-1}$ of $\mathrm{H}_{2} \mathrm{O}$-Res significantly reduced spontaneous pain for 75 min fully revoking $\Delta$ Weight difference $15 \mathrm{~min}$ after treatment $\left(-1.2 \pm 2.5 \mathrm{~g}\right.$, CFA $+\mathrm{H}_{2} \mathrm{O}$-Res vs $65.0 \pm 3.0 \mathrm{~g}, \mathrm{CFA}+$ vehicle) (Fig. $4 \mathrm{~d})$.

\subsection{Effect of Capparis spinosa on MIA-induced osteoarthritis}

The pain reliever effect of Capparis spinosa was evaluated on MIA-induced osteoarthritis model in the rat. On day 14 , roots ( 300 , 100,30 and $\left.10 \mathrm{mg} \mathrm{kg}^{-1}\right)$, DEC (100, 30 and $\left.3 \mathrm{mg} \mathrm{kg}^{-1}\right), \mathrm{EtH}_{2} \mathrm{O}$ (300, 100, 30 and $\left.10 \mathrm{mg} \mathrm{kg}^{-1}\right), \mathrm{CH}_{2} \mathrm{Cl}_{2}$ (30,10, 3 and $1 \mathrm{mg} \mathrm{kg}^{-1}$ ) or $\mathrm{H}_{2} \mathrm{O}$-Res $\left(100,30\right.$ and $3 \mathrm{mg} \mathrm{kg}^{-1}$ ) from Capparis spinosa were acutely administered p.o. and behavioral tests were performed.

On day 14, MIA injection was able to decrease the pain threshold in response to a mechanical noxious stimulus as measured by Paw pressure test (Figs. 5 and 6). Roots and $\mathrm{EtH}_{2} \mathrm{O}$ exerted a similar effect. The higher dose $\left(300 \mathrm{mg} \mathrm{kg}^{-1}\right)$ significantly increased the weight tolerated on the ipsilateral paw of MIA-injected rats up to $45 \mathrm{~min}$ peaking $15 \mathrm{~min}$ after injection $(60.6 \pm 1.2 \mathrm{~g}$, $\mathrm{MIA}+$ roots and $59.3 \pm 0.6 \mathrm{~g}$, MIA $+\mathrm{EtH}_{2} \mathrm{O}$ ) (Fig. 5a and c). Furthermore, 100 and $30 \mathrm{mg} \mathrm{kg}^{-1}$ of roots, $\mathrm{EtH}_{2} \mathrm{O}$ and DEC showed the same tendency in decreasing pain sensitivity.

As shown in Fig. $6 \mathrm{a}, \mathrm{CH}_{2} \mathrm{Cl}_{2}$ and $\mathrm{H}_{2} \mathrm{O}$-Res were the most effective. Thirty and $10 \mathrm{mg} \mathrm{kg}^{-1} \mathrm{CH}_{2} \mathrm{Cl}_{2}$ extract similarly increased the 


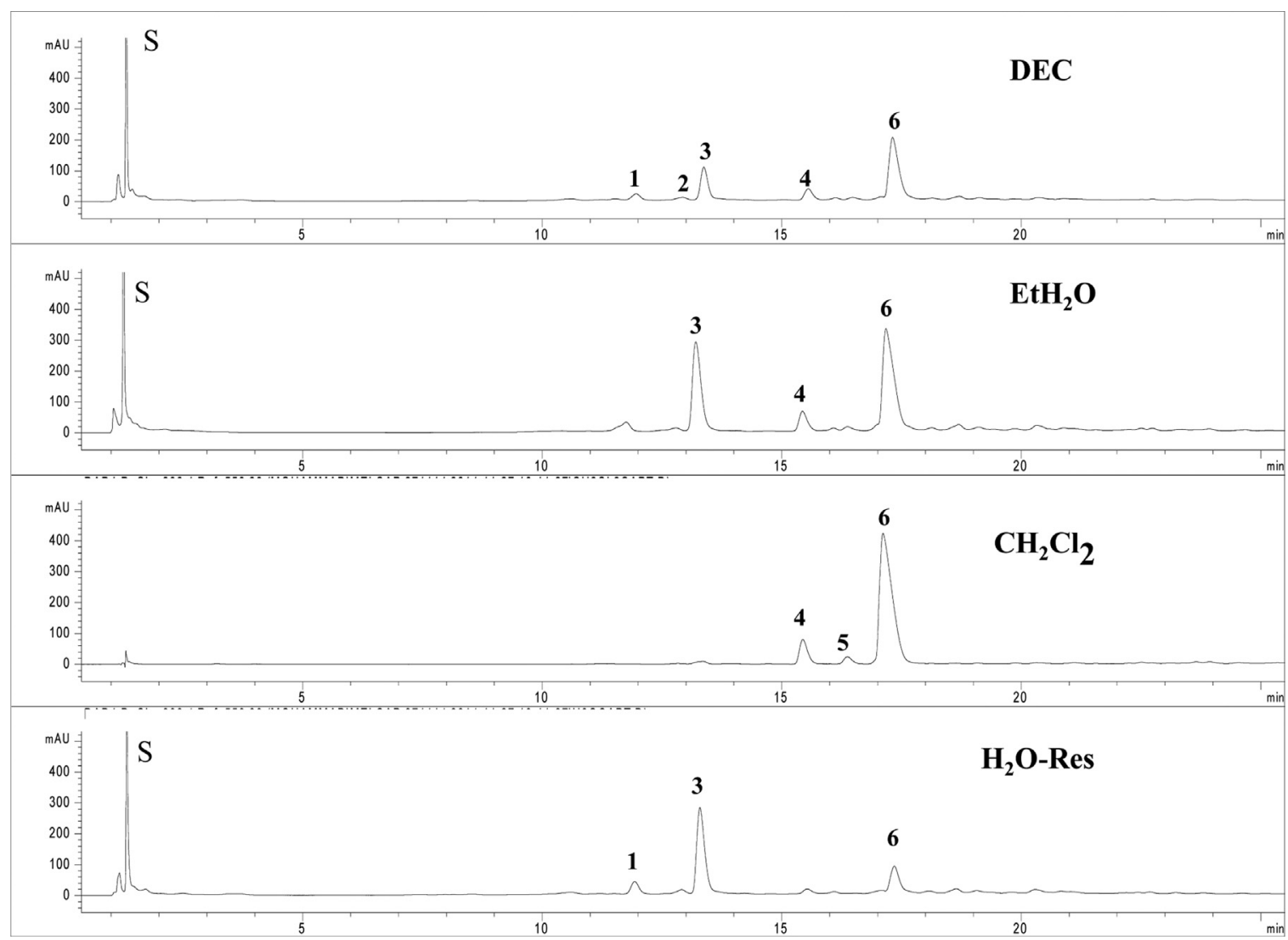

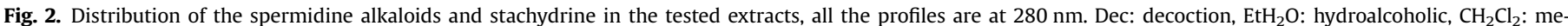

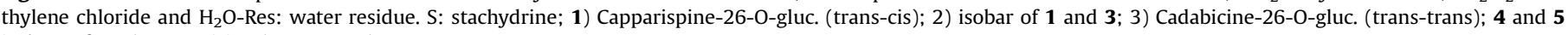
isobars of $6 ; \mathbf{6}$ ) Capparisine (trans-trans).

Table 1

Spermidine alkaloids and stachydrine in the four extracts obtained by Caparis root.

\begin{tabular}{|c|c|c|c|c|c|}
\hline \multirow{2}{*}{$\begin{array}{l}\text { Molecular } \\
\text { weight }\end{array}$} & \multirow[t]{2}{*}{ Compounds } & \multicolumn{4}{|c|}{$\mathrm{mg} / \mathrm{g} \mathrm{DE}$} \\
\hline & & DEC & $\mathrm{EtH}_{2} \mathrm{O}$ & $\mathrm{CH}_{2} \mathrm{CL}_{2}$ & $\mathrm{H}_{2} \mathrm{O}$-Res \\
\hline 598.27 & $\begin{array}{l}\text { 1-Capparispine-26-O- } \\
\text { gluc. }\end{array}$ & 0.28 & 0.59 & - & 0.49 \\
\hline 598.27 & 2-Isobar of $\mathbf{1}$ and $\mathbf{3}$ & 0.19 & 0.38 & - & 0.29 \\
\hline 598.27 & 3-Cadabicine-26- O-gluc. & 1.45 & 3.16 & 1.98 & 3.10 \\
\hline 436.22 & 4-Isobar of 6 & 0.42 & 0.81 & - & 0.23 \\
\hline 436.22 & 5 -Isobar of 6 & 0.12 & 0.20 & 8.06 & 0.21 \\
\hline \multirow[t]{3}{*}{436.22} & 6-Capparisine & 2.75 & 5.05 & 57.44 & 1.29 \\
\hline & $\begin{array}{l}\text { Total spermidine } \\
\text { alkaloids }\end{array}$ & 5.21 & 10.19 & 67.49 & 5.62 \\
\hline & Stachydrine & 54.15 & 51.40 & - & 55.09 \\
\hline
\end{tabular}

DE: dried extract. (1) Capparispine-26-O-gluc. (trans-cis); (2) isobar of $\mathbf{1}$ and 3; (3) Cadabicine-26- O-gluc. (trans-trans); 4 and $\mathbf{5}$ isobars of 6; (6) Capparisine (trans-trans).

pain threshold, being effective for $45 \mathrm{~min}$ and peaking $15 \mathrm{~min}$ after injection $\left(63.3 \pm 0.7 \mathrm{~g}\right.$, MIA $+\mathrm{CH}_{2} \mathrm{Cl}_{2} 30 \mathrm{mg} \mathrm{kg}^{-1}$ and $60.8 \pm 0.7 \mathrm{~g}$, $\mathrm{MIA}+\mathrm{CH}_{2} \mathrm{Cl}_{2} 10 \mathrm{mg} \mathrm{kg}^{-1}$ vs $43.3 \pm 0.7 \mathrm{~g}$, MIA + vehicle). Thirty mg kg ${ }^{-1} \mathrm{H}_{2} \mathrm{O}$-Res displayed comparable effectiveness to the same dosage of the $\mathrm{CH}_{2} \mathrm{Cl}_{2}$ fraction, whereas $100 \mathrm{mg} \mathrm{kg}^{-1}$ significantly increased the withdrawal threshold up to $60 \mathrm{~min}$ revoking pain $15 \mathrm{~min}$ after administration $\left(68.3 \pm 0.7 \mathrm{~g}, \mathrm{MIA}+\mathrm{H}_{2} \mathrm{O}-\mathrm{Res} v s\right.$ $43.0 \pm 0.5 \mathrm{~g}, \mathrm{MIA}+$ vehicle) (Fig. $6 \mathrm{~b}$ ). $\mathrm{ED}_{50}$ values calculated on the bases of this test (MIA, Table 2) allow to establish the following potency order: $\mathrm{H}_{2} \mathrm{O}-\mathrm{Res}>\mathrm{DEC}>\mathrm{CH}_{2} \mathrm{Cl}_{2}>\mathrm{EtH}_{2} \mathrm{O}>$ roots.

Incapacitance test revealed that the different weight burdened between the contralateral and the ipsilateral hind $\operatorname{limb}(\Delta$ Weight) was significantly decreased in MIA injected rats with respect to the sham group (Figs. 5 and 6). As depicted in Fig. $5 \mathrm{~d}$ and $\mathrm{f}$, $300 \mathrm{mg} \mathrm{kg}^{-1}$ both roots and $\mathrm{EtH}_{2} \mathrm{O}$ reduced spontaneous pain in a comparable manner while $100 \mathrm{mg} \mathrm{kg}^{-1}$ roots exerted higher effectiveness $15 \mathrm{~min}$ after injection in comparison to the same dosage of $\mathrm{EtH}_{2} \mathrm{O} \quad(20.3 \pm 0.2 \mathrm{~g}$, MIA+roots vs $45.1 \pm 0.9 \mathrm{~g}$ $\mathrm{MIA}+\mathrm{EtH}_{2} \mathrm{O}$ ). Moreover, $100 \mathrm{mg} \mathrm{kg}^{-1}$ of DEC exerted longer effect being active up to $45 \mathrm{~min}$ (Fig. $5 \mathrm{e}$ ). $\mathrm{CH}_{2} \mathrm{Cl}_{2}$ extract reduced $\Delta$ Weight in a dose dependent-manner (Fig. 6c). Notably, the higher dose significantly lowered hind limb bearing alterations up to $60 \mathrm{~min}$ peaking $15 \mathrm{~min}$ after administration $(3.7 \pm 2.2 \mathrm{~g}$, $\mathrm{MIA}+\mathrm{CH}_{2} \mathrm{Cl}_{2}$ extract vs $61.0 \pm 2.0 \mathrm{~g}$, MIA + vehicle). Thirty $\mathrm{mg} \mathrm{kg}^{-1}$ $\mathrm{H}_{2} \mathrm{O}$-Res was lower effective than the same dose of $\mathrm{CH}_{2} \mathrm{Cl}_{2}$ fraction whereas $100 \mathrm{mg} \mathrm{kg}^{-1}$ significantly decreased spontaneous pain for 75 min (Fig. 6d).

\section{Discussion}

The present results highlight the pain reliever effect of root powder and four different root extracts from Capparis spinosa in two different models of articular pain.

Alkaloids like capparisine, cadabicine in free and glycosylate forms are known as main components of $C$. spinosa root (Fu et al., 2008) together with a more polar alkaloid, stachydrine (Khatib et al., 2016). These alkaloids are differently distributed in the four samples. DEC and $\mathrm{EtH}_{2} \mathrm{O}$ extracts show very similar profiles at $280 \mathrm{~nm}$ but the total amount of spermidine alkaloids is almost double in the latter sample, while the amount of stachydrine is similar. After the fractionation step it was possible to obtain a 

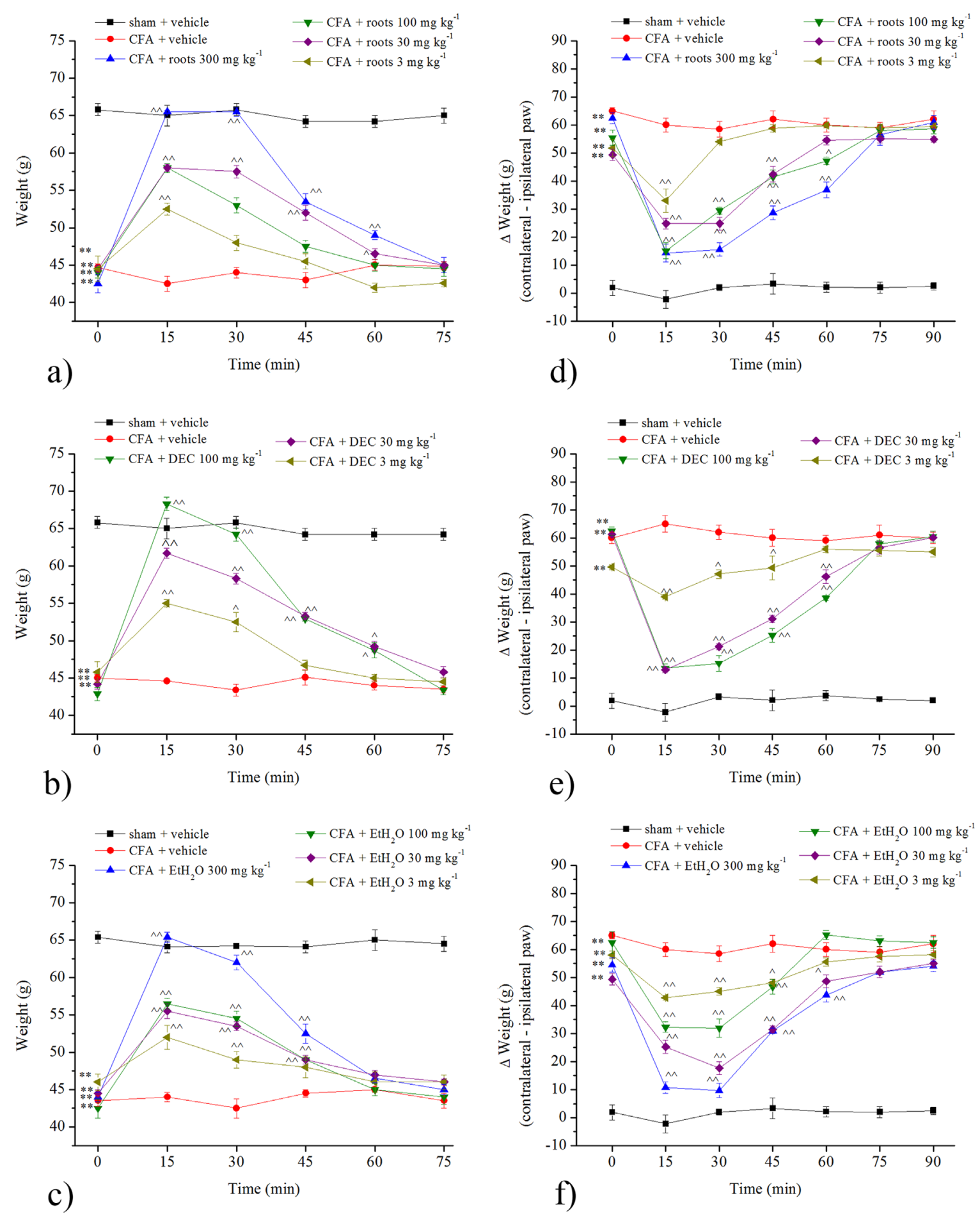

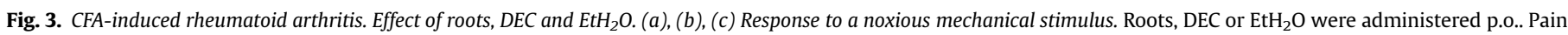

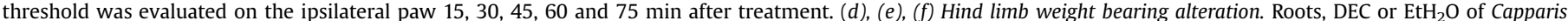

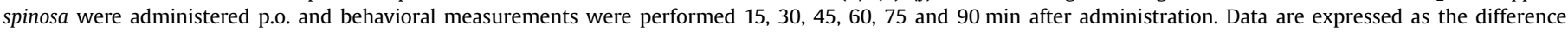

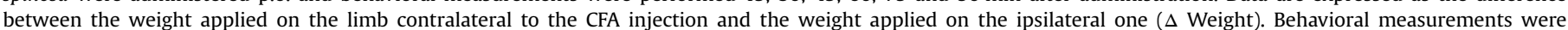

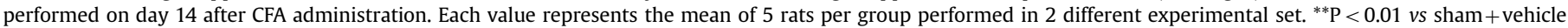
treated rats; ${ }^{\wedge} \mathrm{P}<0.05$ and ${ }^{\wedge} \wedge \mathrm{P}<0.01$ vs $\mathrm{CFA}+$ vehicle treated rats.

$\mathrm{CH}_{2} \mathrm{Cl}_{2}$ extract with total spermidine alkaloids concentration up to 7 times higher with respect to the native sample $\left(\mathrm{EtH}_{2} \mathrm{O}\right)$, mostly composed by capparisine (6) and free of stachydrine. As expected, in the residual water fraction the glycosylated forms, capparispine-26-O-glucoside (1) and cadabicine-26-O-glucoside (3) were the more abundant alkaloids, together with stachydrine in a concentration close to that in decoction. As highlighted from the phytochemical analyses, it was possible to evaluate samples with different alkaloid contents and ratios among the target molecules, trying to identify the more active compounds.

The intra-articular injection of the Complete Freund's adjuvant induced inflammatory arthritis with similar features to rheumatoid arthritis (Waksman, 2012). CFA-induced arthritis causes a painful condition starting 3 days after injection and peaking on 


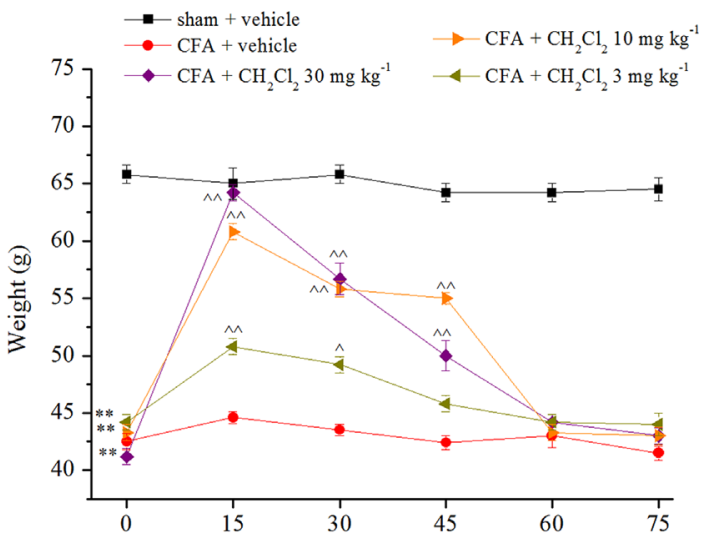

a)

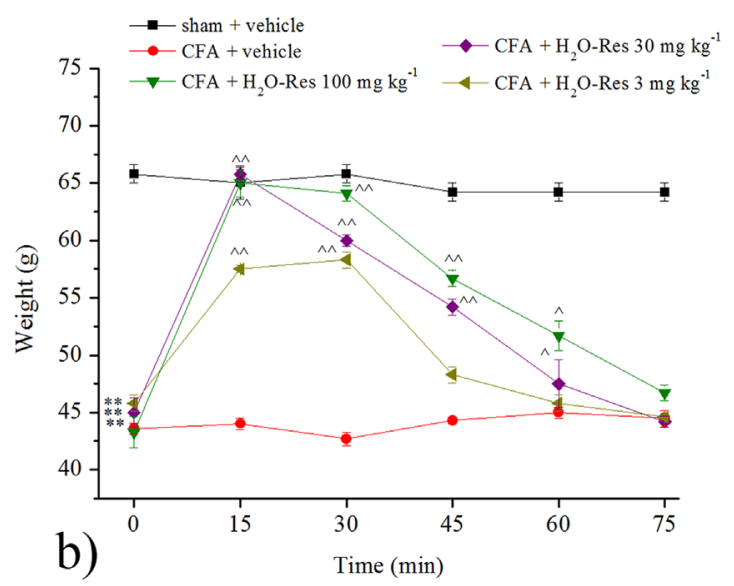

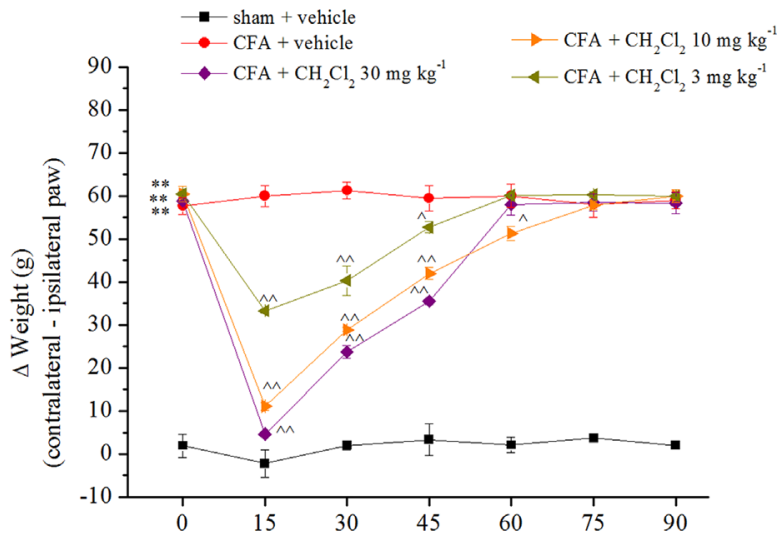

c)

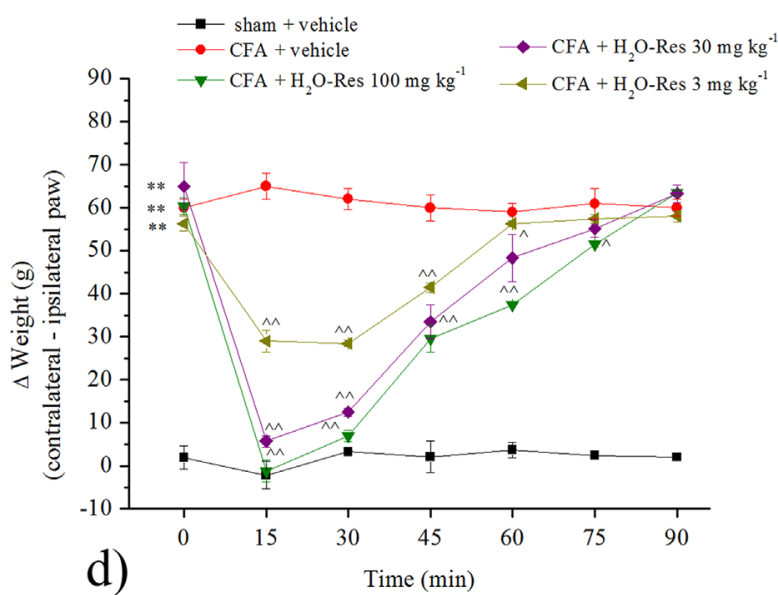

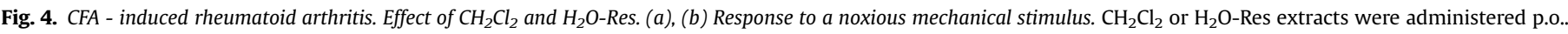

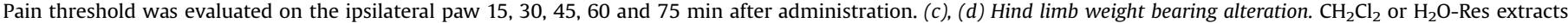

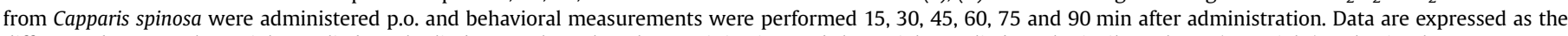

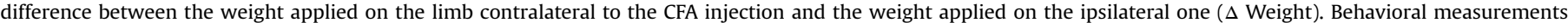

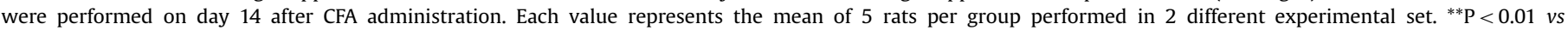
sham + vehicle treated rats; ${ }^{\wedge} \mathrm{P}<0.05$ and ${ }^{\wedge} \wedge \mathrm{P}<0.01$ vs $\mathrm{CFA}+$ vehicle treated rats.

Table 2

$\mathrm{ED}_{50}$ values.

\begin{tabular}{ll}
\hline Compounds & $\mathbf{E D}_{\mathbf{5 0}}\left(\mathbf{m g ~ k g}^{-\mathbf{1}}\right)$ \\
\hline CFA, roots & $15.1 \pm 2.4$ \\
CFA, DEC & $12.5 \pm 1.9$ \\
CFA, EtH $\mathrm{CH}_{2} \mathrm{O}$ & $24.4 \pm 3.7$ \\
$\mathrm{CFA}, \mathrm{CH}_{2} \mathrm{Cl}_{2}$ & $4.6 \pm 1.0$ \\
$\mathrm{CFA}, \mathrm{H}_{2} \mathrm{ORes}$ & $0.9 \pm 0.5$ \\
MIA, roots & $46.2 \pm 5.6$ \\
MIA, DEC & $1.5 \pm 0.9$ \\
MIA, $\mathrm{EH}_{2} \mathrm{O}$ & $11.2 \pm 3.7$ \\
MIA, $\mathrm{CH}_{2} \mathrm{Cl}_{2}$ & $4.8 \pm 2.1$ \\
MIA, $\mathrm{H}_{2} \mathrm{O}-\mathrm{Res}$ & $0.4 \pm 0.2$ \\
\hline
\end{tabular}

$\mathrm{ED}_{50}$ values were calculated on the Paw pressure test results $30 \mathrm{~min}$ after the administration of the different vegetal products both in the CFA and MIA model.

day 14 (Di Cesare Mannelli et al. 2013a; Luo et al., 2014). Fourteenth days after CFA injection, the weight tolerated on the ipsilateral paw sensibly decreased. At the same time the postural unbalance, as measure of spontaneous pain, increased in CFA-injected rats. Root powder as well as root extracts are active in reducing pain behaviour. The $\mathrm{CH}_{2} \mathrm{Cl}_{2}$ and $\mathrm{H}_{2} \mathrm{O}$-Res extracts (30 $\mathrm{mg} \mathrm{kg}^{-1}$ ) were the most potent in increasing pain threshold and reducing spontaneous pain. DEC (100 $\left.\mathrm{mg} \mathrm{kg}^{-1}\right)$ showed higher potency in comparison to $\mathrm{EtH}_{2} \mathrm{O}$ and roots $\left(300 \mathrm{mg} \mathrm{kg}^{-1}\right.$ ). A similar pain reliever profile was highlighted in the rat model of osteoarthritis induced by the intra-articular injection of MIA. The first inflammatory phase (day 7 after MIA injection) is followed by an increasing neuropathic component leading to enhanced responses to normal or suprathreshold stimulation (allodynia- and hyperalgesia-related measurements; Di Cesare Mannelli et al., 2013b). On day 14, Capparis spinosa preparations relieved MIAdependent articular pain (both hypersensitivity and spontaneous pain) showing efficacy also against a predominantly neuropathic pain. The better efficacy/potency profile was shown by the $\mathrm{CH}_{2} \mathrm{Cl}_{2}$ and $\mathrm{H}_{2} \mathrm{O}$-Res extracts. DEC was able to decrease mechanical hypersensitivity and postural unbalance at dosages lower than $\mathrm{EtH}_{2} \mathrm{O}$. However, the higher dose of DEC did not allow to revert the painful condition.

Pharmacological data suggest that the enrichment in spermidine alkaloids $\left(\mathrm{CH}_{2} \mathrm{Cl}_{2}\right)$ allows to potentiate the pain reliever effect in comparison to the less concentrated extracts DEC and $\mathrm{EtH}_{2} \mathrm{O}$. Surprisingly, efficacy and potency were not lost by the residual aqueous product $\mathrm{H}_{2} \mathrm{O}$-Res characterized by a lower concentration of non-glycosylated spermidine alkaloids as capparisine (6) and its isobars. It can be underlined that all these alkaloids have a macro cyclic ring that contains a linear chain overlapped with the structure of spermidine, a well known endogenous polyamine. Typically, these compounds are formed by the condensation of a nitrogen atom with a carboxylic acid and the nucleophilic attack of 

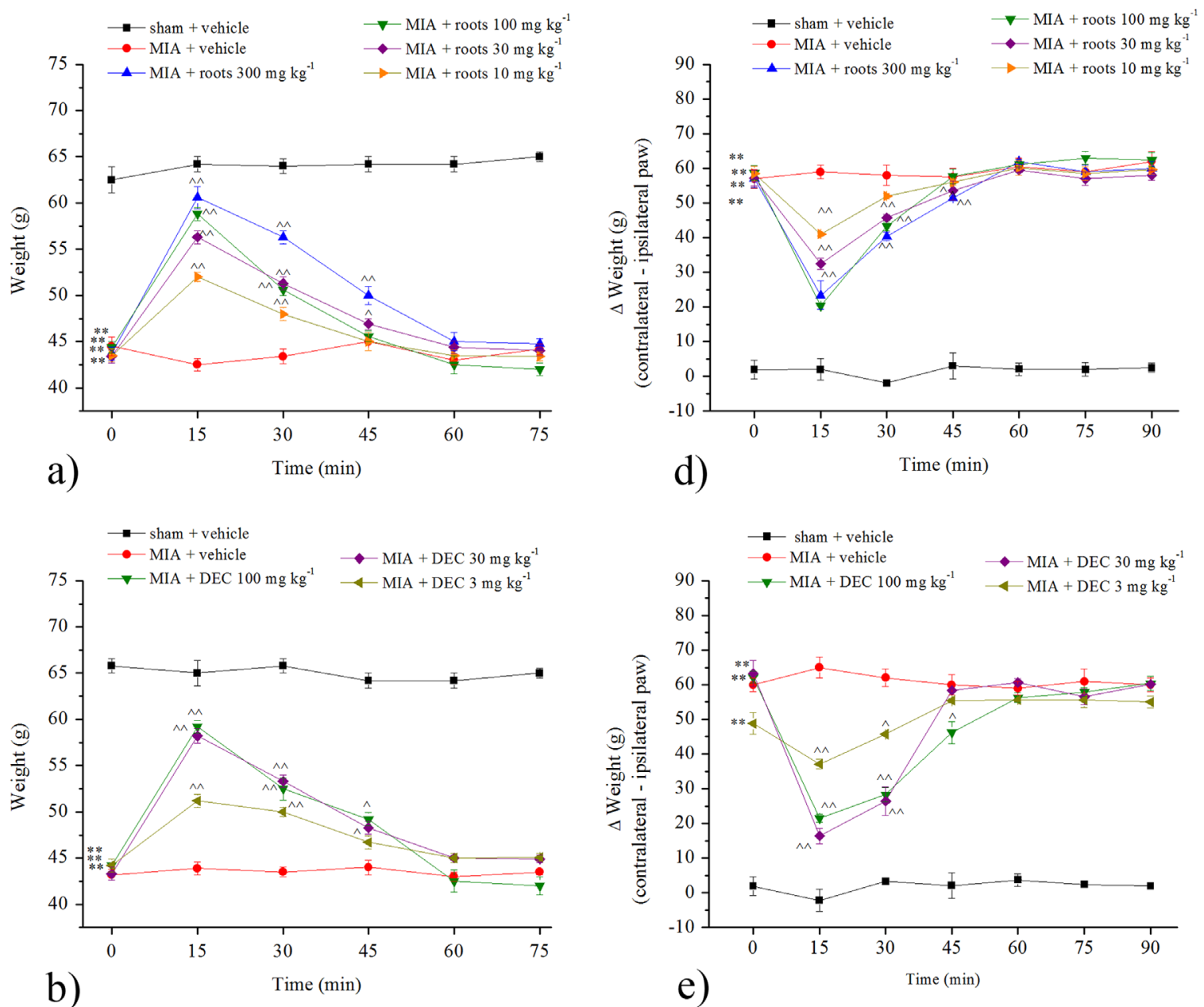

b)

Time (min)
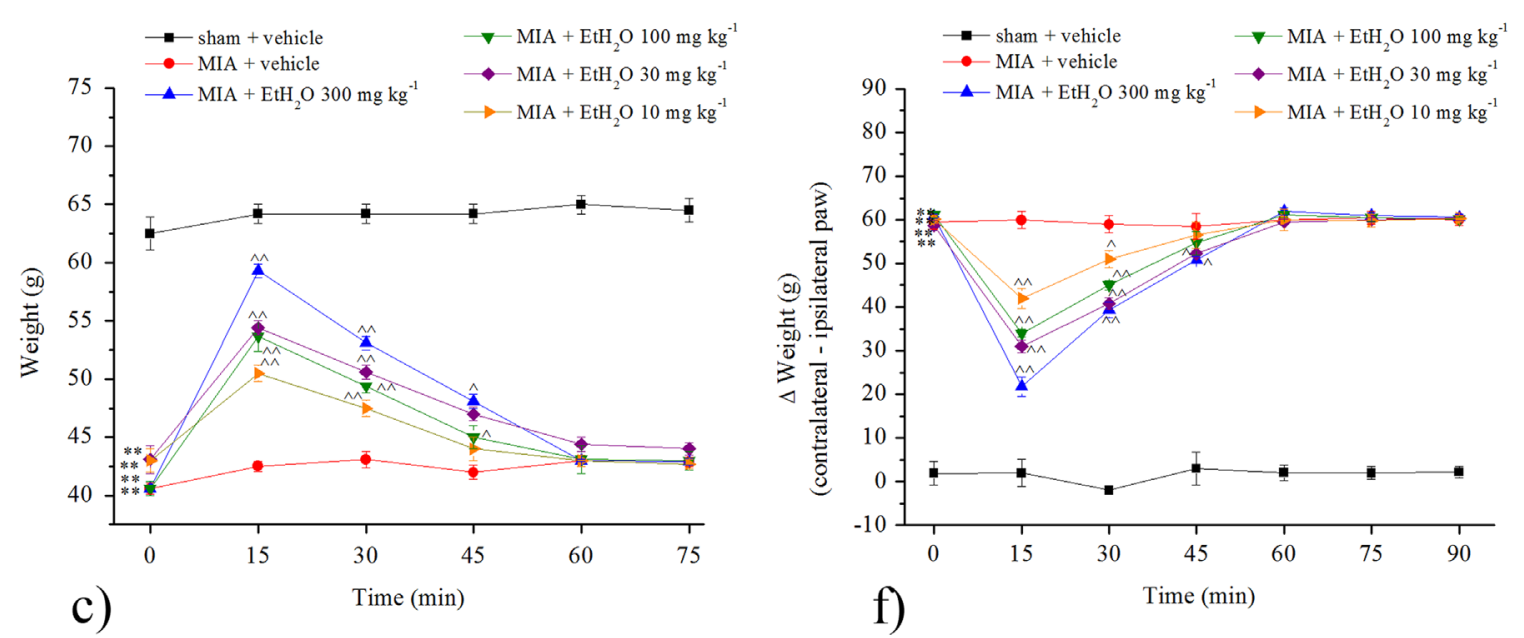

Fig. 5. MIA - induced osteoarthritis. Effect of roots, $\mathrm{DEC}$ and $\mathrm{EtH}_{2} \mathrm{O}$. (a), (b), (c) Response to a noxious mechanical stimulus. Roots, DEC or EtH $\mathrm{H}_{2} \mathrm{O}$ were administered p.o.. Pain threshold was evaluated on the ipsilateral paw 15, 30, 45 and 60 min after administration. (d), (e), (f) Hind limb weight bearing alteration. Roots, DEC or EtH $\mathrm{H}_{2} \mathrm{O}$ of Capparis spinosa were administered p.o. and behavioral measurements were performed 15, 30, 45 and 60 min after administration. Data are expressed as the difference between the weight applied on the limb contralateral to the MIA injection and the weight applied on the ipsilateral one ( $\Delta$ Weight). Behavioral measurements were performed on day 14 after MIA administration. Each value represents the mean of 5 rats per group performed in 2 different experimental set. ${ }^{* *} \mathrm{P}<0.01$ vs sham + vehicle treated rats; ${ }^{\wedge} \mathrm{P}<0.05$ and $\wedge^{\wedge} \mathrm{P}<0.01$ vs MIA + vehicle treated rats.

the second nitrogen on an electrophilic center in the carboxylic unit (Cordell, 1981).

It is well known that the use of polyamines in arthritis could be beneficial for synovial bearing reconstruction and reduce osteolytic activity (Iezaki et al., 2012). Moreover, continuous nociceptive stimulation caused by joint inflammation leads to spinal dorsal horn's neurons hyperexcitability inducing neuropathic pain (Fernihough et al., 2004; Lee et al., 2011). The present results suggests that the pain reliever effect of caper could be due to the anti-inflammatory and protective effects of spermidine alkaloids as well as to the presence of other phyto-chemicals able to reduce the firing of sensitive neurons. Accordingly, Arslan et al. (2010) showed that the 


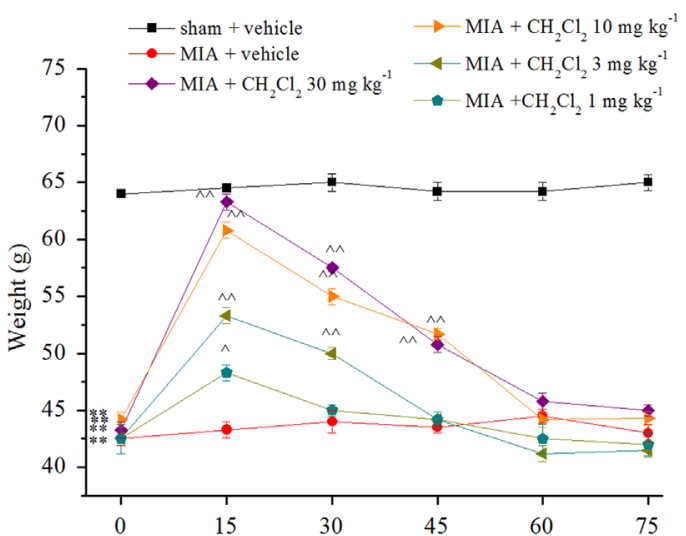

a)

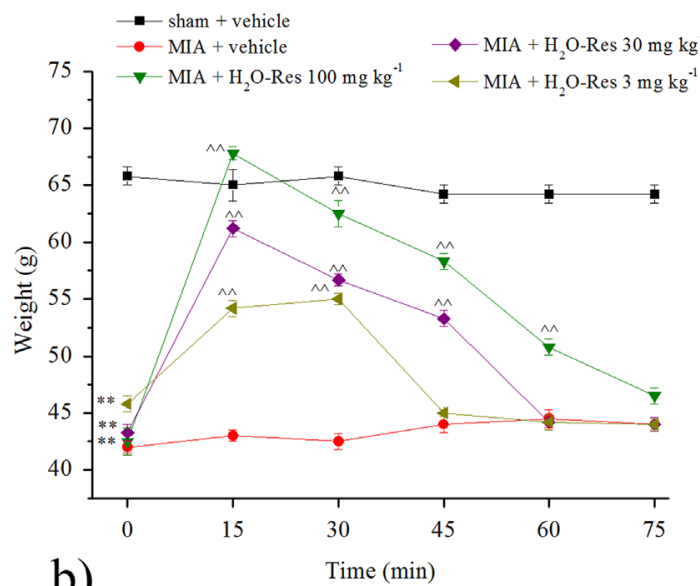

b)
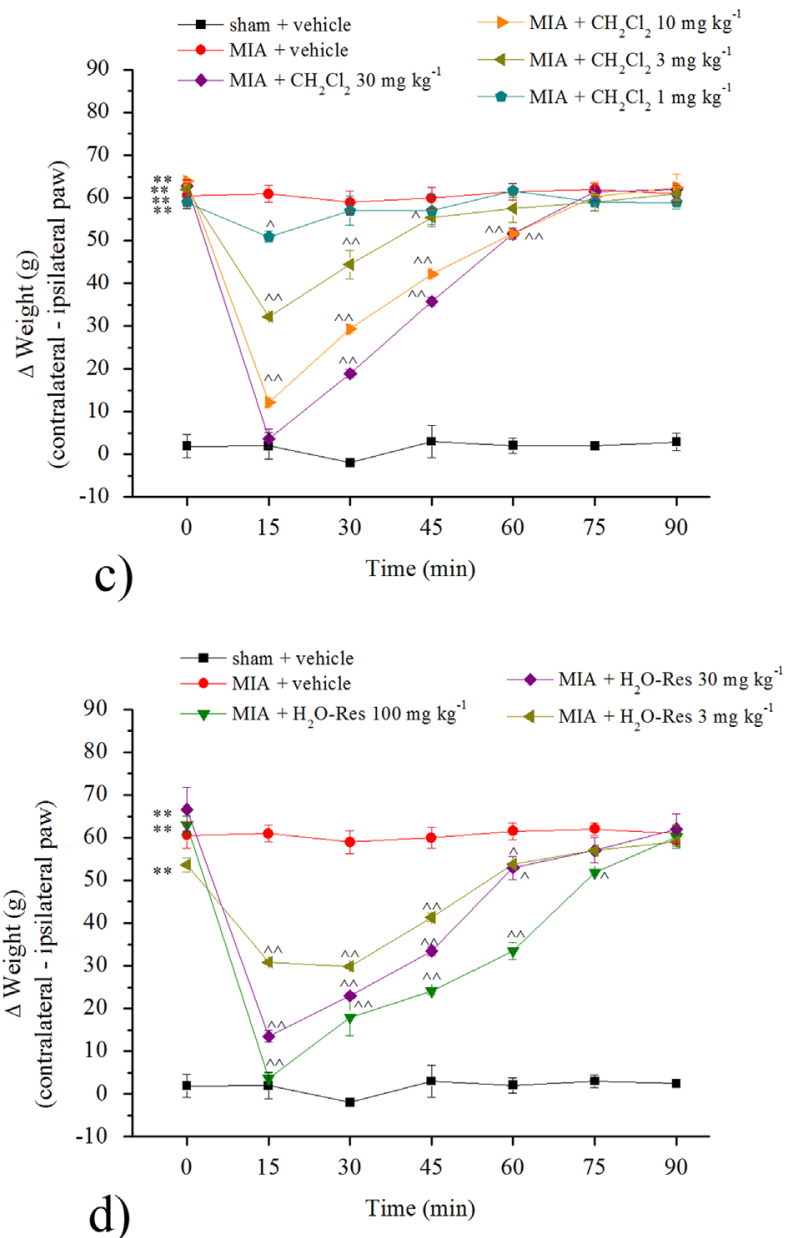

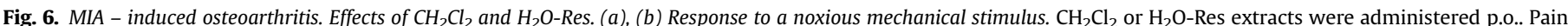

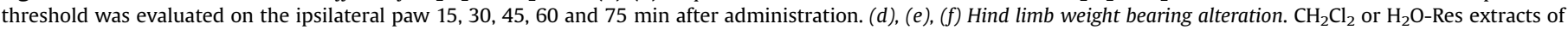

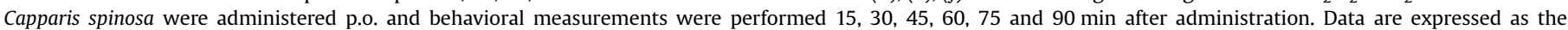

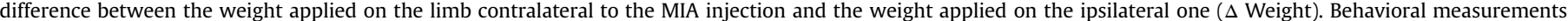

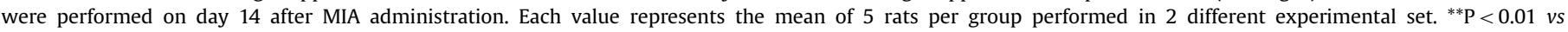
sham + vehicle treated rats; ${ }^{\wedge} \mathrm{P}<0.05$ and ${ }^{\wedge} \wedge \mathrm{P}<0.01$ vs $\mathrm{MIA}+$ vehicle treated rats.

bud extract of Capparis ovata, exerted anti-nociceptive action through both peripheral and central mechanisms. Finally, applying different chromatographic methods and after a depth investigation by mass spectrometry, the presence of other potential active compounds such as quercetin or other flavonoids, which could exert anti-oxidative activity, was excluded. Noteworthy, flavonoids are widely distributed in the aerial parts of different plants but usually lower amounts are found in the underground parts, as roots. An intense oxidative state in the presence of chondrocyte necrosis has been observed at the joint level both in MIA and CFA arthritis models (Di Cesare Mannelli et al., 2013a). Moreover, a direct relationship between persistent pain and oxidative stress has been demonstrated (Di Cesare Mannelli et al., 2012). Several authors suggested the relevance of the anti-oxidant effects of quercetin and other flavonoids in the pain reliever properties of Capparis spinosa fruit extracts (Feng et al., 2011; Zhou et al., 2010). Furthermore, flowering buds of Capparis spinosa can counteract necrosis of chondrocytes and trigger lowering of NO synthase and oxygen radicals in an in vitro model of articular damage (Panico et al., 2005). Nevertheless, and according to our results, the presence of these flavonols in caper root has not been demonstrated to date. Taking into account stachydrine, it does not emerge a key role of this polar alkaloid that is almost in the same amounts in DEC, $\mathrm{EtH}_{2} \mathrm{O}$ and $\mathrm{H}_{2} \mathrm{O}$ Res but completely absent in $\mathrm{CH}_{2} \mathrm{Cl}_{2}$ sample.

\section{Conclusions}

In conclusion, Capparis spinosa root powder and its different extracts are able to acutely relieve pain in rat models of rheumatoid arthritis and osteoarthritis. Our data support the traditional use of this root against different types of pain in humans. Since the efficacy was not influenced by the different alkaloid distribution throughout the extracts, a real synergistic effect due to a specific "phytochemical mixture" can be hypothesized.

\section{Acknowledgements}

This research was funded by the Italian Ministry of Instruction, University and Research (MIUR) and by the University of Florence. The authors declare no conflict of interest.

\section{Appendix A. Supporting information}

Supplementary data associated with this article can be found in the online version at http://dx.doi.org/10.1016/j.jep.2016.09.032. 


\section{References}

Al-Said, M.S., Abdelsattar, E.A., Khalifa, S.I., El-Feraly, F.S., 1988. Isolation and identification of an anti-inflammatory principle from Capparis spinosa. Pharmazie 43, 640-641.

Arslan, R., Bektas, N., Ozturk, Y., 2010. Antinociceptive activity of methanol extract of fruits of Capparis ovata in mice. J. Ethnopharmacol. 131 (1), 28-32.

Batanouny, K., Drissamnauer, L., 2005. Capparis spinose L A guide to medicinal plants in North Africa. Center for Mediterranean Cooperation, IUCN, pp. 71-74.

Baytop, P., 1984. Therapy with Medicinal Plants (Past and Present). Istanbul University Publications, Istanbul.

Bijlsma, J.W., Berenbaum, F., Lafeber, F.P., 2011. Osteoarthritis: an update with relevance for clinical practice. Lancet 377 (9783), 2115-2126.

Buckingham, J., 1994. Dictionary of Natural Products 5. Chapman \& Hall, London, p. 5228.

Çalis, I., Kurüzüm, A., Rüedi, P., 1999. 1H-Indole-3-acetonitrile glycosides from Capparis spinosa fruits. Phytochemistry 50, 1205-1208.

Cordell, G.A., 1981. Introduction to Alkaloids, A Bioenergetics Approach. Wiley-Interscience, New York.

Di Cesare Mannelli, L., Bani, D., Bencini, A., Brandi, M.L., Calosi, L., Cantore, M., Carossino, A.M., Ghelardini, C., Valtancoli, B., Failli, P., 2013a. Therapeutic effects of the superoxide dismutase mimetic compound MnIIMe2DO2A on experimental articular pain in rats. Mediators Inflamm. 2013, 905360.

Di Cesare Mannelli, L., Micheli, L., Zanardelli, L., Ghelardini, C.M., 2013b. Low dose native type II collagen prevents pain in a rat osteoarthritis model. BMC Musculoskelet. Disord. 14, 228.

Di Cesare Mannelli, L., Zanardelli, M., Failli, P., Ghelardini, C., 2012. Oxaliplatin-induced neuropathy: oxidative stress as pathological mechanism. Protective effect of silibinin. J. Pain 13 (3), 276-284.

Eddouks, M., Lemhadri, A., Michel, J.B., 2004. Caraway and caper: potential antihyperglycaemic plants in diabetic rats. J. Ethnopharmacol. 94, 143-148.

Feng, X., Lu, J., Xin, H., Zhang, L., Wang, Y., Tang, K., 2011. Anti-arthritic active fraction of Capparis spinosa L. fruits and its chemical constituents. Yakugaku Zasshi 131 (3), 423-429.

Fernihough, J., Gentry, C., Malcangio, M., Fox, A., Rediske, J., Pellas, T., Kidd, B. Bevan, S., Winter, J., 2004. Pain related behaviour in two models of osteoarthritis in the rat knee. Pain 112 (1-2), 83-93.

Fu, X.P., Wu, T., Abdurahim, M., Su, Z., Hou, X.L., Aisa, H.A., Wu, H., 2008. New spermidine alkaloids from Capparis spinosa roots. Phytochem. Lett. 1 (1), 59-62.

Goldring, M.B., Marcu, K.B., 2009. Cartilage homeostasis in health and rheumatic diseases. Arthritis Res. Ther. 11 (3), 224.

Hudaib, M., Mohammad, M., Bustanji, Y., Tayyem, R., Yousef, M., Abuirjeie, M., Aburjai, T., 2008. Ethnopharmacological survey of medicinal plants in Jordan, Mujib Nature Reserve and surrounding area. J. Ethnopharmacol. 120 (1), 63-71.

Iezaki, T., Hinoi, E., Yamamoto, T., Ishiura, R., Ogawa, S., Yoneda, Y., 2012.
Amelioration by the natural polyamine spermine of cartilage and bone destruction in rats with collagen-induced arthritis. Pharmacol. Sci. 119 (1), 107-111.

Inocencio, C., Alcaraz, F., Calderón, F., Obón, C., Rivera, D., 2002. The use of floral characters in Capparis sect. Capparis to determine the botanical and geographical origin of capers. Eur. Food Res. Technol. 214, 335-339.

Jiang, H.E., Li, X., Ferguson, D.K., Wang, Y.F., Liu, C.J., Li, C.S., 2007. The discovery of Capparis spinosa L. (Capparidaceae) in the Yanghai Tombs (2800 years bp), NW China, and its medicinal implications. J. Ethnopharmacol. 113 (3), 409-420.

Khatib, M., Pieraccini, G., Innocenti, M., Melani, F., Mulinacci, N., 2016. An insight on the alkaloid content of Capparis spinosa L. root by HPLC-DAD-MS, MS/MS and $1 \mathrm{H}$ qNMR. J. Pharm. Biomed. Anal. 123, 53-62 (Epub ahead of print).

Lee, Y.C., Nassikas, N.J., Clauw, D.J., 2011. The role of the central nervous system in the generation and maintenance of chronic pain in rheumatoid arthritis, osteoarthritis and fibromyalgia. Arthritis Res. Ther. 13 (2), 211.

Leighton, G.E., Rodriguez, R.E., Hill, R.G., Hughes, J., 1988. k-opioid agonist produce antinociception after i.v. and i.c.v. but not intrathecal administration in the rat. Br. J. Pharm. 93, 553-560.

Luo, J.G., Zhao, X.L., Xu, W.C., Zhao, X.J., Wang, J.N., Lin, X.W., Sun, T., Fu, Z.J., 2014. Activation of spinal NF-KB/p65 contributes to peripheral inflammation and hyperalgesia in rat adjuvant-induced arthritis. Arthritis Rheuma. 66 (4), 896-906.

Moghaddasi, M.S., Kashani, H.H., Azarbad, Z., 2012. Capparis spinosa L. propagation and medicinal uses. Life Sci. J. 9 (4), 684-686.

Mullen, L.M., Chamberlain, G., Sacre, S., 2015. Pattern recognition receptors as potential therapeutic targets in inflammatory rheumatic disease. Arthritis Res. Ther. 17 (1), 122.

Panico, A.M., Cardile, V., Garufi, F., Puglia, C., Bonina, F., Ronsisvalle, G., 2005. Protective effect of Capparis spinosa on chondrocytes. Life Sci. 77 (20), 2479-2488.

Sangha, O., 2000. Epidemiology of rheumatic diseases. Rheumatology 39 (Suppl 2), S3-S12.

Scott, D.L., Wolfe, F., Huizinga, T.W., 2010. Rheumatoid arthritis. Lancet 376 (9746), 1094-1108.

Sher, H., Alyemeni, M.N., 2010. Ethnobotanical and pharmaceutical Evaluation of Capparis spinosa L, validity of local folk and Unani System of Medicine. J. Med. Plants Res. 4 (17), 51-1756.

Tlili, N., Elfalleh, W., Saadaoui, E., Khaldi, A., Triki, S., Nasri, N., 2011. The caper (Capparis L.): ethnopharmacology, phytochemical and pharmacological properties. Fitoterapia 82 (2), 93-101.

Waksman, B.H., 2002. Immune regulation in adjuvant disease and other arthritis models: relevance to pathogenesis of chronic arthritis. Scand. J. Immunol. 56 (1), 12-34.

Zhou, H., Jian, R., Kang, J., Huang, X., Li, Y., Zhuang, C., Yang, F., Zhang, L., Fan, X., Wu, T., Wu, X., 2010. Anti-inflammatory effects of Caper (Capparis spinosa L.) fruit aqueous extract and the isolation of main phytochemicals. J. Agric. Food Chem. 58 (24), 12717-12721. 